\title{
An Injectable Hyaluronic Acid-Based Composite Hydrogel by DA Click Chemistry With pH Sensitive Nanoparticle for Biomedical Application
}

\author{
Xiaohong Hu ${ }^{1 \star t}$, Ziyu Gao ${ }^{1 \dagger}$, Huaping Tan ${ }^{2}$, Huiming Wang ${ }^{1}$, Xincheng $\mathrm{Mao}^{1}$ and \\ Juan Pang ${ }^{1}$
}

${ }^{1}$ School of Material Engineering, Jinling Institute of Technology, Nanjing, China, ${ }^{2}$ Biomaterials for Organogenesis Laboratory, School of Materials Science and Engineering, Nanjing University of Science and Technology, Nanjing, China

OPEN ACCESS

Edited by:

Xing Wang,

Institute of Chemistry (CAS), China

Reviewed by:

Qingchen Cao,

Institute of Chemistry (CAS), China

Li Ziyi,

Sun Yat-sen University, China Yun-Long Wu,

Xiamen University, China

${ }^{*}$ Correspondence:

Xiaohong Hu

huxiaohong07@163.com

these authors have contributed equally to this work as co-first authors

Specialty section:

This article was submitted to Polymer Chemistry,

a section of the journal

Frontiers in Chemistry

Received: 23 April 2019 Accepted: 20 June 2019 Published: 03 July 2019

Citation:

Hu X, Gao Z, Tan H, Wang H, Mao X and Pang J (2019) An Injectable

Hyaluronic Acid-Based Composite Hydrogel by DA Click Chemistry With

pH Sensitive Nanoparticle for Biomedical Application.

Front. Chem. 7:477.

doi: 10.3389/fchem.2019.00477
Hydrogels with multifunctional properties attracted intensively attention in the field of tissue engineering because of their excellent performance. Also, object-oriented design had been supposed to an effective and efficient method for material design as cell scaffold in the field of tissue engineering. Therefore, a scaffold-oriented injectable composite hydrogel was constructed by two components. One was $\mathrm{pH}$-sensitive bifunctional nanoparticles for growth factor delivery to improve biofunctionability of hydrogel scaffold. The other was Diels-alder click crosslinked hyaluronic acid hydrogel as matrix. $\mathrm{pH}$ dependent release behavior of nanoparticle component was confirmed by results. And, its bioactivity was verified by in vitro cell culture evaluation. In consideration of high-efficiency and effectiveness, low toxicity, controllability and reversibility, dynamic covalent and reversible Diels-alder click chemistry was used to design a HA hydrogel with two kinds of crosslinking points. The properties of hydrogel like gelation time and swelling ratio were influenced by $\mathrm{pH}$ value and polymer concentration. Composite hydrogel was formed by in situ polymerization, which exhibited acceptable mechanical property as a scaffold for biomedical field. Lastly, in vitro evaluation from results of viability, DNA content and cell morphology confirmed that hydrogels could maintain cell activity and support cell growth. Compared with pure hydrogel, composite hydrogel possessed better properties.

Keywords: hydrogel, Diels-alder click chemistry, pH-sensitive nanoparticle, cell scaffold, growth factor delivery

\section{INTRODUCTION}

Hydrogel, a water-swollen polymer network, is widely used in fields of biomedical fields due to their physiological-like aqueous environment (Bai et al., 2017; Celie et al., 2019; Massaro et al., 2019; Song et al., 2019; Zhao et al., 2019). Among its applications, scaffold-oriented hydrogel for biomedical application has an extra request of biofunctionability besides general characteristic of low toxicty and aqueous environment (Fu et al., 2012; Yu et al., 2013; Fan et al., 2015; Oh et al., 2016; Williams et al., 2017; Thanusha et al., 2018; Wang C. Z. et al., 2018; Zhu et al., 2018; Celie et al., 2019; Massaro et al., 2019; Song et al., 2019; Zhao et al., 2019). In consideration of natural component of extracellular matrix (ECM), hyaluronic acid (HA), as one of main component of ECM, is an optimal material to fabricate hydrogel for tissue engineering (Yu et al., 2013; Williams et al., 2017; Wang C. Z. et al., 2018; Zhu et al., 2018; Massaro et al., 2019). However, HA itself cannot 
form hydrogel naturally in solution due to absence of reactive groups or physical interactions. In early years, chemical crosslinkers were used to form HA hydrogels. But the toxicity of chemical crosslinker cannot satisfy the request of biocompatibility for cell scaffold, especially for that in situ formation scaffold. Recently, many efforts had been made to introduce function groups to $\mathrm{HA}$ main chain, which can be further crosslinked by their reaction though click chemistry, Michael addition and shift base reaction etc. ( $\mathrm{Yu}$ et al., 2013; Bai et al., 2017). Although these attempts had been made great progress for HA hydrogel as cell scaffold, they could not be satisfied all requests as scaffold for all kinds of cells. Therefore, HA hydrogels with specific functions for specific cells and environment are also needed. Recently, as for crosslinking reaction, diels-alder clickchemistry has showed favorite characteristics for cell scaffold fabrication due to its low toxicity, high efficiency, moderate reaction condition, and reversible characteristic (Franc et al., 2009; Yu et al., 2013; Bai et al., 2017; Banerjee et al., 2017). Herein, HA hydrogel with self-healing property was designed through Diels-alder click chemistry as a cell scaffold to support cell growth.

Besides scaffold matrix properties, bioactive factors play important roles on cell proliferation and function expression (Akuta et al., 2015; Azevedo et al., 2015; Psarra et al., 2015; Muraoka et al., 2018). However, bioactive protein is liable to loss its function due to the transformation of secondary structure, which was induced by external stimuli. Therefore, one objective of our research is to realize the effective and efficient delivery of growth factor into cells, simultaneously maintaining the bioactivity of growth factor. Since heparin is a verified negative polysaccharide to protect the bioactivity of growth factor, it has been used in a great number of scaffold or carriers for growth factor protection (Psarra et al., 2015; Wu et al., 2015; Song et al., 2018). Another challenge is how to realize the precise delivery to cells. Stimulus from difference between intracellular and extracellular environment including $\mathrm{pH}$ value, enzyme, biotin-avidin interaction have been applied to carrier design and preparation for growth factor delivery. In view of mild acid condition of intracellular environment $(\mathrm{pH}$ 5.5-6.0), low $\mathrm{pH}$ responsive nanoparticle would be considered to be an effective carrier for growth factor delivery. Herein, a dualstructural $\mathrm{pH}$ sensitive nanocarrier for growth factor delivery was designed using $\mathrm{pH}$-sensitive acetalated $\beta$-cyclodextrin (Ac- $\beta$-CD) as main body for $\mathrm{pH}$ response property and heparin nanogel as interpenetrating component for growth factor protection. The bioactivity of released growth factor was evaluated by in vitro cell behavior indicator like cell viability, DNA content and cell morphology. In the further step, the nanocarrier was incorporated with HA hydrogel to form composite hydrogel as cell scaffold, which was in vitro evaluated by 1-week cell growth.

\section{EXPERIMENT}

\section{Material}

4-(4,6-dimethoxy triazine)-4-methyl morpholine hydrochloride (DMTMM), furylmethylamine, adipicdihydrazide (ADH), maleimide modified PEG (mal-PEG-mal), 2-morpholinoethane sulfonic acid (MES), heparin (HEP), and 3-aminopropyl methacrylate (AMA) were purchased from Aladdin. Dimethyl sulfoxide (DMSO), dichloromethane (DCM), sodium periodate, ammonium persulfate (APS), N,N,N'N'tetramethylethylenediamine (TEMED), and gelatin were purchased from Shanghai Chemical Industries Co. Ltd (China). Hyaluronate acid (HA, Mw $=1,000 \mathrm{kDa}$ ) was obtained from Shandong Furuida Co., China. Trypsin, Dulbecco's modified Eagle's medium (DMEM) and 3-(4, 5-dimethyl) thiazol-2,5dimethyl tetrazolium bromide (MTT) were obtained from Sigma. Fetal bovine serum (FBS) was purchased from Sijiqing biotech. Co., China. PicoGreen dsDNA Assay Kit was bought from Thermo Fisher Scientific. Ac- $\beta-C D$ was synthesized previously. All other reagents and solvents were of analytical grade and used as received.

\section{Synthesis and Characterization of Polysaccharide Derivatives}

Synthesized processes of polysaccharide derivatives were shown in Scheme 1. HEP-AMA and HA-furan were synthesized by amidation between polysaccharides and functional chemical containing amine groups (furylmethylamine or AMA). Briefly, about $0.5 \mathrm{~g}$ HA or HEP was first dissolved in $150 \mathrm{~mL} 100 \mathrm{mM}$ MES buffer solution. Seven hundred milligram of DMTMM were successively added into the solution to activate carboxyl groups for $30 \mathrm{~min}$ under magnetic stirring. After activation, $1.5 \mathrm{mmol}$ functional chemical (furylmethylamine or AMA) was dropped or added to reaction system, which was continued to react for $24 \mathrm{~h}$ under dark at room temperature. Then the final solution was dialyzed with dialysis bag of $10 \mathrm{kDa}$ cut-off molecular weight for 3 days to remove unreacted chemicals and byproduct of small molecule weight. Finally, polysaccharide derivative (HEPAMA or HA-furan) was obtained by freeze drying at $-60^{\circ} \mathrm{C}$ at a pressure of 7-8 $\mathrm{Pa}$.

HA-furan-ADH was also obtained by amidation. Briefly, after $700 \mathrm{mg}$ of DMTMM were used to activate carboxyl groups of $150 \mathrm{~mL} 3.3 \mathrm{mg} / \mathrm{mL}$ HA-furan buffer solution containing $100 \mathrm{mM}$ MES for $30 \mathrm{~min}$ under magnetic stirring, $1.5 \mathrm{mmol}$ $\mathrm{ADH}$ was added to react with HA-furan at room temperature for $24 \mathrm{~h}$. Then HA-furan-ADH was finally obtained after the solution was dialyzed and freeze-dried according to abovementioned conditions.

HA-furan-CHO was synthesized by oxidation of sodium periodate. Briefly, $5 \mathrm{~mL} 0.5 \mathrm{~mol} / \mathrm{L}$ sodium periodate was dropped into $100 \mathrm{~mL} 5 \mathrm{mg} / \mathrm{mL} \mathrm{HA}$-furan solution to oxide HA. After the reaction continued for $2 \mathrm{~h}, 1 \mathrm{~mL}$ ethylene glycol was added to end the reaction. Then HA-furan-CHO was finally obtained after the solution was dialyzed and freeze-dried according to above-mentioned conditions.

These derivatives were characterized by ${ }^{1} \mathrm{H}$ nuclear magnetic resonance $\left({ }^{1} \mathrm{H}\right.$ NMR, Bruker, AV500) using $\mathrm{D}_{2} \mathrm{O}$ as solvent. Grafting ratio of functional molecules for polysaccharides derivatives was calculated by ${ }^{1} \mathrm{H}$ NMR spectra except grafting ratio of aldehyde group, which was qualified by the t-butyl carbazate assay. 


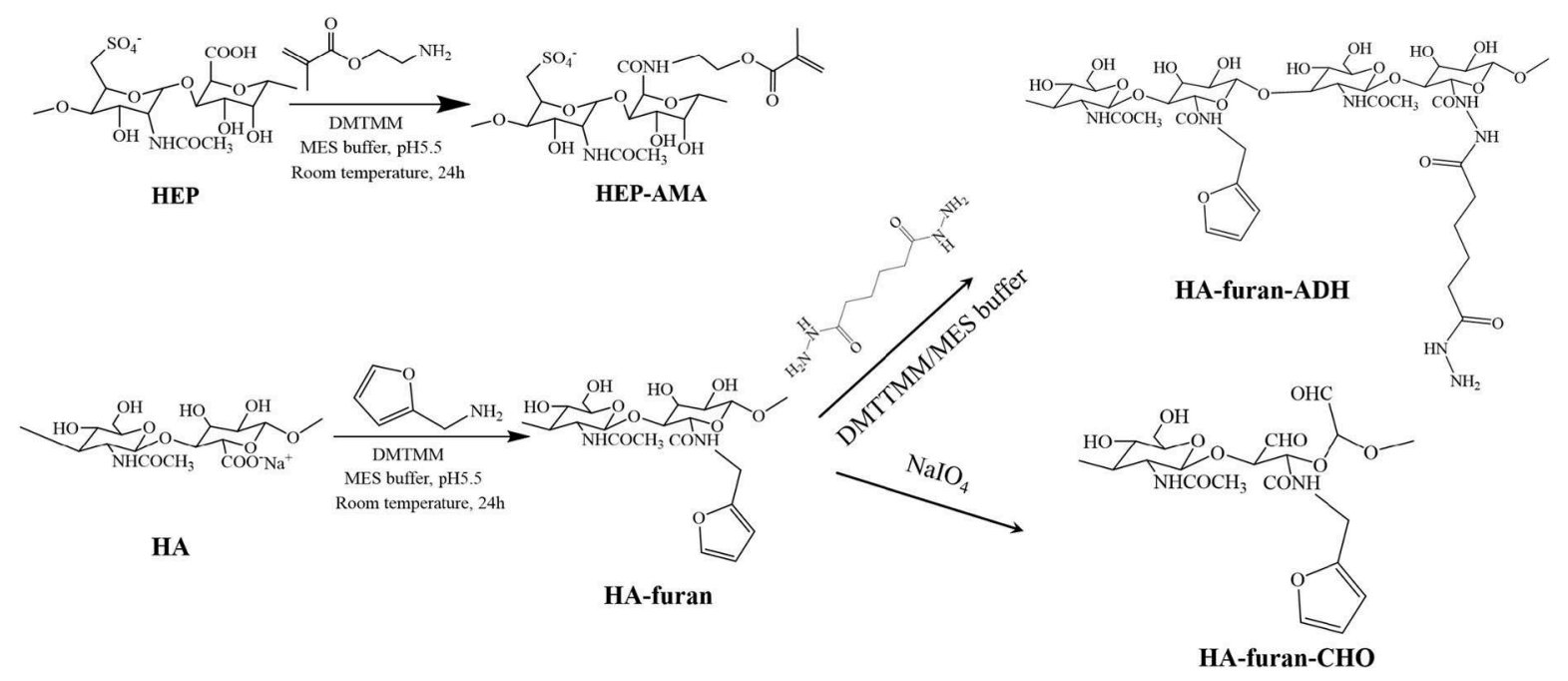

SCHEME 1 | Scheme of synthesis for polysaccharide derivatives.

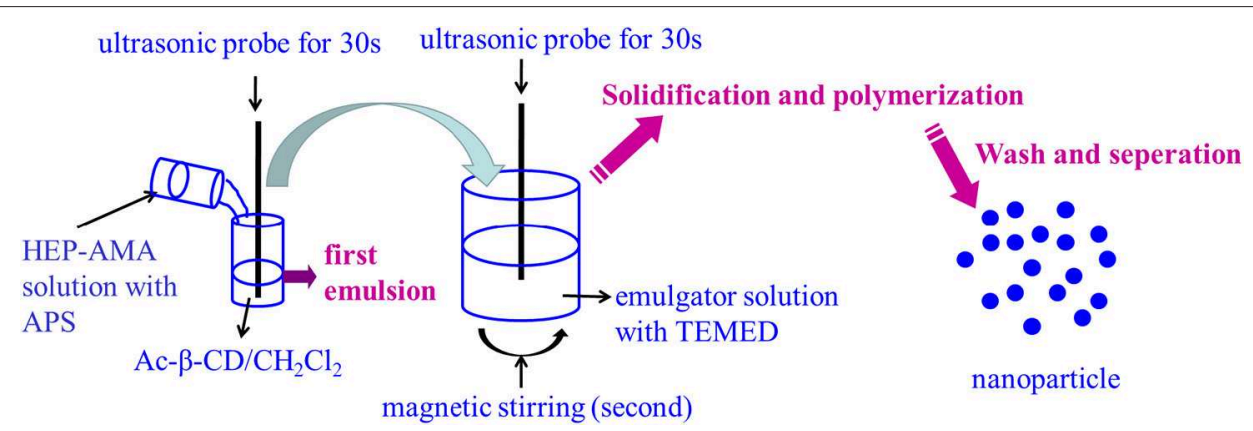

SCHEME 2 | Scheme illustration to show the formation of nanoparticle.

\section{Preparation and Characterization of pH-Sensitive Bifunctional Nanoparticle}

$\mathrm{pH}$-sensitive bifunctional nanoparticles were also fabricated by double emulsion method using previous synthesized $\mathrm{pH}$ sensitive Ac- $\beta-C D$ as a main material (Chen et al., 2017, 2018; Wang X. et al., 2018). The process of preparation was shown in Scheme 2. Briefly, $200 \mu \mathrm{L} 40 \%$ HEP-AMA solution containing $50 \mathrm{mM}$ APS was first emulsified into $1 \mathrm{~mL}$ of $10 \% \mathrm{w} / \mathrm{v}$ Ac- $\beta$ $\mathrm{CD} / \mathrm{DCM}$ solution, which was further emulsified into $5 \mathrm{~mL}$ of $3 \%$ $\mathrm{w} / \mathrm{v}$ gelatin aqueous solution containing $50 \mathrm{mM}$ TEMED. Either first or second emulsion was formed under the help of sonication dispersion method, which was carried out by ultrasonic probe with $1 \mathrm{~kW}$ for $30 \mathrm{~s}$ per step. The obtained emulsion was immediately added into $20 \mathrm{~mL}$ of $1 \% \mathrm{w} / \mathrm{v}$ gelatin solution to evaporate DCM under magnetic stirring. At the same time, HEPAMA was crosslinked by radical polymerization to form nanogel structure. Finally, nanoparticles were collected by centrifugation $(14,000 \mathrm{rpm}, 10 \mathrm{~min})$ after $10 \mathrm{~h}$. The collected nanoparticles were washed several times by basic water $\left(\mathrm{pH} 8.0\right.$, adjusted by $\left.\mathrm{NH}_{3}\right)$ and lyophilized to obtain dry nanoparticle powder. The $\mathrm{pH}$ sensitive nanoparticles were resuspended into basic water $(\mathrm{pH}$ 8.0, adjusted by $\mathrm{NH}_{3}$ ) to form diluted nanoparticle suspension (lower than $100 \mu \mathrm{g} / \mathrm{mL}$ ) by ultrasonic probe for $1 \mathrm{~min}$ and further characterized by dynamic light scattering (DLS, nano ZS). In morphology investigation, $50 \mu \mathrm{L}$ of resuspended nanoparticles was dried on silica layer for scanning electron microscope (SEM, S8100), and another $50 \mu \mathrm{L}$ was dried on copper mesh for transmission electron microscope (TEM, Tecnai 12) at $200 \mathrm{kV}$.

\section{In vitro Evaluation of VEGF Delivery Property and Bioactivity Performance}

VEGF165 was loaded into nanoparticle through absorbance. Briefly, nanoparticle was dispersed in VEGF165 solution. After the mixture was vibrated for $24 \mathrm{~h}$ at $4{ }^{\circ} \mathrm{C}$ to load VEGF165, nanoparticle was centrifuged to remove unloaded growth factor. The loaded amount was calculated by the difference of VEGF165 concentration between before and after growth factor loading, which was determined by ELISA kit. For VEGF165 release assay, $120 \mathrm{mg}$ VEGF165 encapsulated nanoparticle was dispersed in $4 \mathrm{~mL}$ PBS under vibration at $37^{\circ} \mathrm{C}$. At appropriate intervals, $500 \mu \mathrm{L}$ released solution was withdrawn after centrifuged and qualified by ELISA kit. Simultaneously, $500 \mu \mathrm{L}$ fresh solution was supplemented into released solution.VEGF165 concentration of each interval was obtained by referring to the standard curve. 
The cumulative released VEGF165 was calculated by VEGF165 amount of each interval.

The released VEGF165 was co-cultured with HUVEC cells for its bioactivity evaluation. Briefly, VEGF165 was released in DMEM medium with $30 \mathrm{mg} / \mathrm{mL}$ for $12 \mathrm{~h}$. The released medium was collected for further use. HUVEC cells were incubated in a humidified atmosphere of $95 \%$ air and $5 \% \mathrm{CO}_{2}$ at $37^{\circ} \mathrm{C}$. The used cells were detached using $0.25 \%$ trypsin in PBS for the experiment. Then $100 \mu \mathrm{L}$ (or $1 \mathrm{~mL}$ ) of the released medium were added into each well of 96-well (or 12-well) culture plate, into which the $100 \mu \mathrm{L}$ (or $1 \mathrm{~mL}$ ) cell suspension with cell density of $2^{*} 10^{4}$ cell/mL was subsequently added. Cell viability (MTT assay), DNA content and cell morphology were characterized as a function of cultural time. For MTT assay, $20 \mu \mathrm{L}$ MTT was supplemented into each well and successively cultured for another $4 \mathrm{~h}$. Then the absorbance of $200 \mu \mathrm{L}$ MTT/DMSO solution at $560 \mathrm{~nm}$ was recorded by a microplate reader (Infinite M200 PRO).For DNA assay, detached cells of each well (12well culture plate) was digested by $500 \mu \mathrm{L} 10 \mathrm{mg} / \mathrm{mL}$ papain solution at $65^{\circ} \mathrm{C}$ overnight, which was qualified by Quant$\mathrm{iT}^{\mathrm{TM}}$ PicoGreen ${ }^{\circledR}$ dsDNA kit. Finally, cells were observed by fluorescence microscope (IX73).

\section{Hydrogel Formation and Characterization}

$\mathrm{HA}$-furan-ADH and HA-furan-CHO were dissolved in water, respectively, to obtain two kind solutions with certain concentration from 2 to $10 \% \mathrm{w} / \mathrm{v}$. The above-mentioned solutions with same concentration were mixed with equal volume, into which equimolar mal-PEG-mal with furan group on HA derivative was added and stirred. Gelation time was obtained by observation method, which was defined as the interval between mixing and loss of fluidity for mixture. The preparation process for composite nanoparticle was shown in Scheme 3. Briefly, nanoparticle was dispersed in HAfuran-CHO solution with final concentration of $10 \mathrm{mg} / \mathrm{mL}$ in advance. Composite hydrogel was then fabricated by the same method for pure hydrogel preparation. Composite hydrogel was characterized by rheological measurement in a parallel platemode using a strain-controlled rheometer (MCR102). The self-healing property was recorded by digital photos. Firstly, the formed hydrogel was cut into two parts completely. Secondly, two separated part was put together with complete interface touch for $24 \mathrm{~h}$. Finally, the self-healed hydrogel was recorded by digital photos.

\section{In vitro Cell Growth in Composite Hydrogel}

HUVEC cells was incorporated in situ into composite hydrogel during hydrogel formation. Briefly, detached HUVEC cells were added to $10 \%$ HA-furan- $\mathrm{ADH}$ solution to form cell/precursor suspension with cell density of $2^{*} 10^{6} \mathrm{cell} / \mathrm{mL}$. The cell/precursor suspension was mixed with another $10 \% \mathrm{w} / \mathrm{v}$ precursor/nanoparticle suspension with $10 \mathrm{mg} / \mathrm{mL}$ nanoparticle to form composite hydrogel with cells. Into the above-mentioned solution, mal-PEG-mal was added and mixed. Each cell encapsulated hydrogel carrier with final volume of $200 \mu \mathrm{L}$ was put in each well of 24-well culture plate and incubated in a humidified atmosphere of $95 \%$ air and $5 \% \mathrm{CO}_{2}$ at $37^{\circ} \mathrm{C}$. Cytoviability (MTT assay), DNA content and cell morphology (microscope images) were characterized as a function of cultural time. For MTT assay, $100 \mu \mathrm{L}$ MTT was supplemented into each well and successively cultured for another $4 \mathrm{~h}$. Then hydrogel was dissolved by $1 \mathrm{~mL}$ DMSO, the absorbance of $200 \mu \mathrm{L}$ above solution at $560 \mathrm{~nm}$ was recorded by a microplate reader (Infinite M200 PRO). For DNA assay, each gel with cells was digested by $500 \mu \mathrm{L} 10 \mathrm{mg} / \mathrm{mL}$ papain solution at $65^{\circ} \mathrm{C}$ overnight, which was qualified by Quant-iT ${ }^{\mathrm{TM}}$ PicoGreen ${ }^{\circledR}$ dsDNA kit. Finally, cells in hydrogel film were observed by fluorescence microscope (IX73).

\section{Statistical Analysis}

Data were analyzed using the $t$-test for differences. The software of origin was used to calculate these differences for $p$ value. Results were reported as means \pm standard deviation, at least 3 replicates (from different samples) formed by above-mentioned method were analyzed in all experiments. The sample size for hydrogel is about $200 \mathrm{mg}$. The significant level was set at $p<0.05$.

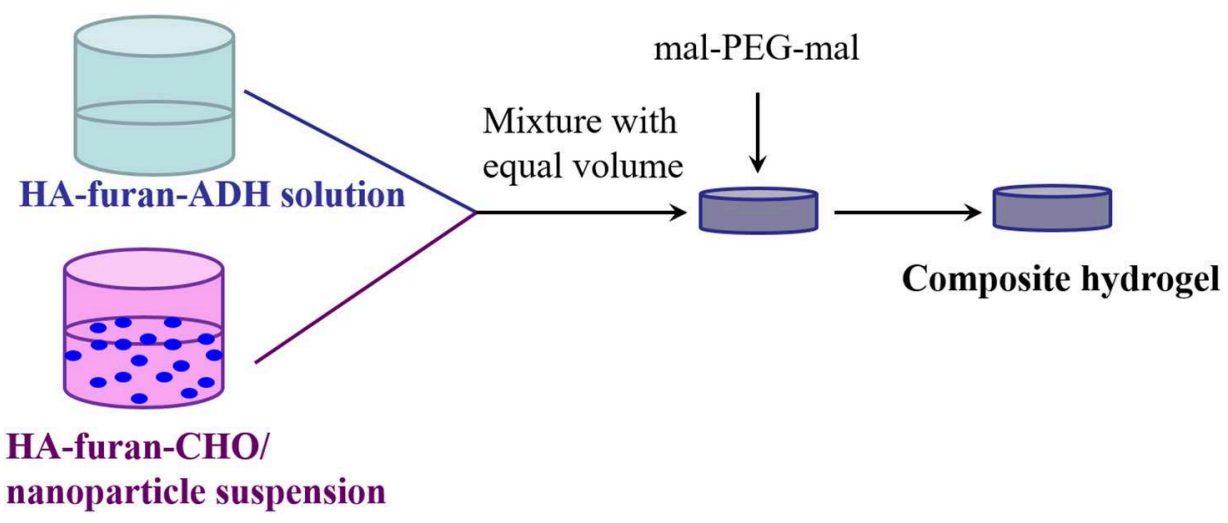

SCHEME 3 | Scheme illustration to show the formation of composite hydrogel. 


\section{RESULT AND DISCUSSION}

\section{pH-Sensitive Bifunctional Nanoparticle Formation}

In order to obtain crosslinkable heparin derivative, HEPAMA was first synthesized and characterized by ${ }^{1} \mathrm{H}$ NMR spectrum in Figure 1. The details of chemical shift are listed as follows: the chemical shift at $1.6 \mathrm{ppm}$ is attributed to the protons of methyl group of AMA at 8 position, the chemical shifts from 3.0 to $4.2 \mathrm{ppm}$ are attributed to the protons of pyranose ring and $-\mathrm{CH}_{2}-\mathrm{O}$ from 1 to 6 position, the chemical shifts at $5.6 \mathrm{ppm}$ and 6.2 are attributed to the protons of $\mathrm{C}=\mathrm{CH}_{2}$ of AMA at 7 position. The chemical shift at 7 position confirmed successful grafting of AMA onto HEP main chain.

$\mathrm{pH}$-sensitive bifunctional nanoparticle was prepared by double emulsion method combined with in situ polymerization (Scheme 2). Final nanoparticle exhibited homogeneous sphere morphology, which was confirmed by SEM image (Figure 2A) and TEM image (Figure 2B). Furthermore, different brightness and obvious boundary was found in the TEM image, which indicated different phase structure. The dark structure might be ascribed to $\mathrm{pH}$ sensitive Ac- $\beta-C D$, while the light structure might be attributed to HEP nanogel. Simultaneously, slight

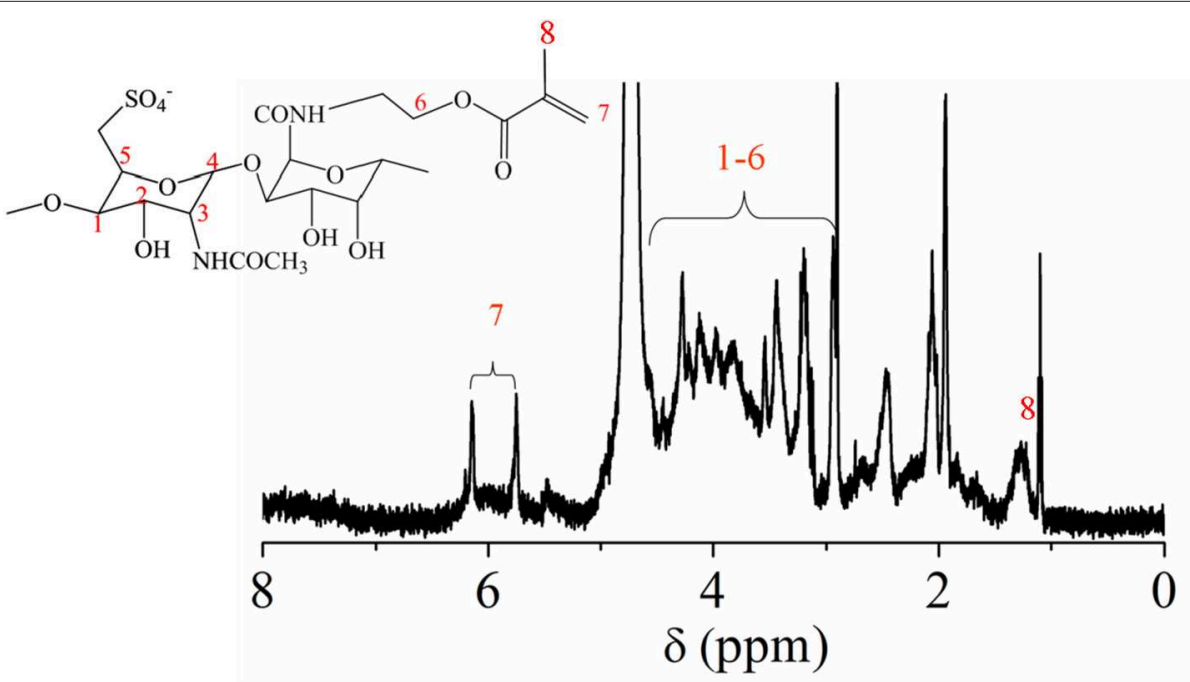

FIGURE 1 | ${ }^{1} \mathrm{H}$ NMR spectrum of HEP-AMA.

A

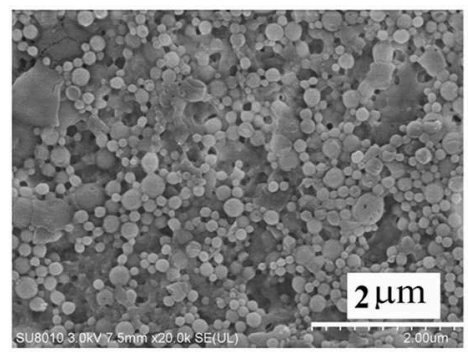

C

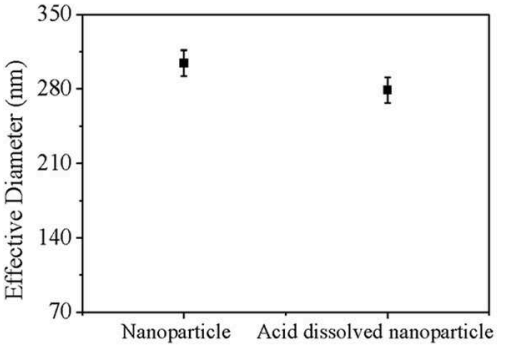

B
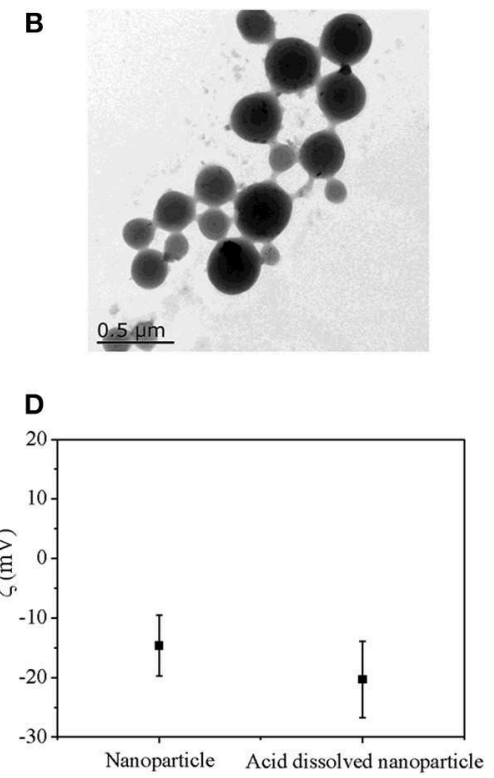

FIGURE 2 | (A) SEM image of nanoparticle; (B) TEM image of nanoparticle; (C) Effective diameter; and (D) zeta potential of nanoparticles determined by DLS. 
adhesive structure was also found in the TEM image, which might be due to slight crosslinking of nanogel during the process of in situ polymerization and conglutination in drying process of HEP nanogel. These results indicated that nanogel had been successfully synthesized during the preparation of nanoparticle. Moreover, effective diameters and zeta potentials of prepared nanoparticles in PBS and in acid were recorded by DLS method, which was shown in Figures 2C,D. Effective diameter of nanoparticle in PBS was $304 \pm 12 \mathrm{~nm}$, which was larger than that in acid solution of $279 \pm 12 \mathrm{~nm}$. However, the difference between them had no significant difference. Since $\mathrm{pH}$ sensitive property of the bifunctional nanoparticle come from Ac- $\beta-C D$ dissolution in acid solution due to degradation of Ac- $\beta-C D$, which was confirmed by transparency variation of nanoparticle suspension, only HEP nanogel existed in acid solution (Chen et al., 2017, 2018; Wang X. et al., 2018). Since nanogel was formed in situ during the fabrication of Ac- $\beta$ CD nanoparticle, they had similar diameter, which was also confirmed by the TEM image (Figure 2B). The zeta potential for nanoparticle in acid solution was larger than that in PBS due to contribution of negative heparin in acid environment. However, no significant difference was found between them. The nanoparticle possessed similar chemical component with nanogel so that they had similar zeta potential except slight influence of $\mathrm{pH}$ value.

\section{In vitro Evaluation for the Bifunctional Nanoparticle}

The growth factor encapsulated capacity and its release behavior in vitro for the bifunctional nanoparticle were investigated in Figures 3A,B. The equilibrium encapsulated growth factor in nanoparticles increased with the initial growth factor's concentration especially when the concentration is lower than $120 \mathrm{ng} / \mathrm{mL}$ (Figure 3A). The maximum growth factor encapsulated capacity was about $1.9 \mathrm{ng} / \mathrm{mg}$ nanoparticles, which condition was also used for further release behavior investigation. In PBS ( $\mathrm{pH} 7.4$ ), about $65 \%$ could be released in $24 \mathrm{~h}$ from nanoparticle, about $50 \%$ growth factor was burst released in the first $2 \mathrm{~h}$ and remaining $15 \%$ growth factor was linearly released from nanoparticles in the following $22 \mathrm{~h}$. In mild acid medium ( $\mathrm{pH} 5.5$ ), nearly all the growth factor dispersed homogeneously in the medium after $1 \mathrm{~h}$ due to degradation of Ac- $\beta$-CD nanoparticle. But it was not sure whether growth factor had been diffused into medium or still incorporated with homogeneous dispersed heparin nanogel.

The bioactivity of released growth factor was evaluated by in vitro cell behavior using cells without growth factor as a control. Cell viability of the growth factor group increased with culture time just as the control group (Figure 4A). Furthermore, cell viability of the growth factor group was significantly higher than
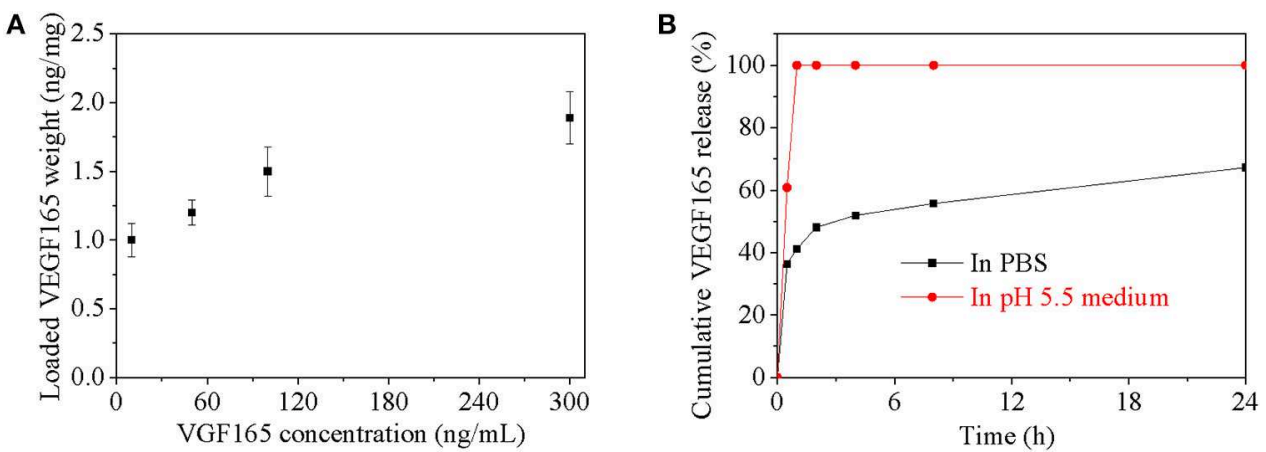

FIGURE 3 | (A) Loaded VEGF165 weight in every microgram nanoparticle as a function of VEGF165 concentration; (B) Cumulative VEGF165 release in PBS with pH value of 7.4
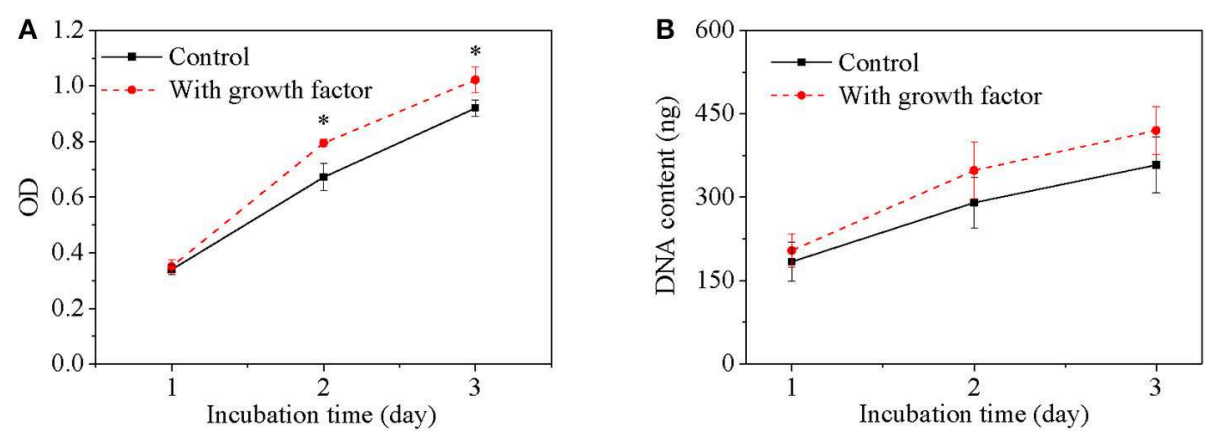

FIGURE 4 | Cell viability (A) and DNA content (B) of cells as a function of culture time. Cell density is 20,000/mL. Two hundred microliter for MTT assay of 96-well TCPs and $2 \mathrm{~mL}$ for DNA assay of 6 -well TCPs. ${ }^{*} p<0.05$. 
the control group especially after cell had been cultured for 2 days. Since DNA content of each cell is constant, DNA content reflects cell number. DNA content of cells for the two groups increased with culture time, while DNA content of cells for the growth factor group was higher than that for the control group (Figure 4B). However, the increase had no significant difference according to statistical analysis. The space of $2 \mathrm{D}$ cell culture for cell growth is limited to a constant value, which may restrict cell proliferation if the space could not accommodate more cells.
Moreover, cell morphology was shown in Figure 5. Cell on TCPs exhibited round-like polygon shape regardless culture time and existence of growth factor (Figures 5A-F). It was also found that the number of cells for the growth factor group is larger than that of the control group, which was consistent with results of cell viability and DNA content. Therefore, the released growth factor could promote cell growth from the above-mentioned results, which indicated released growth factor could maintain its bioactivity.

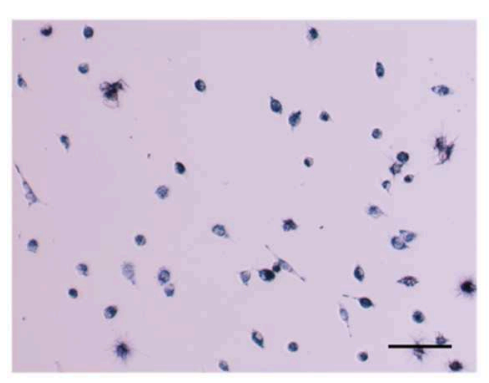

A

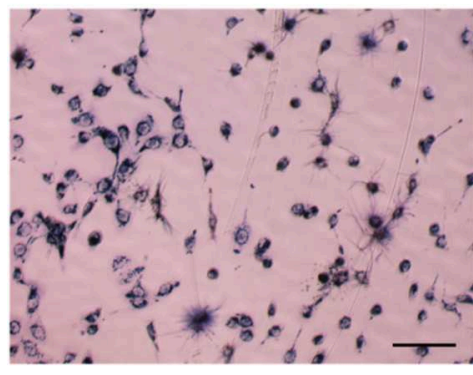

D

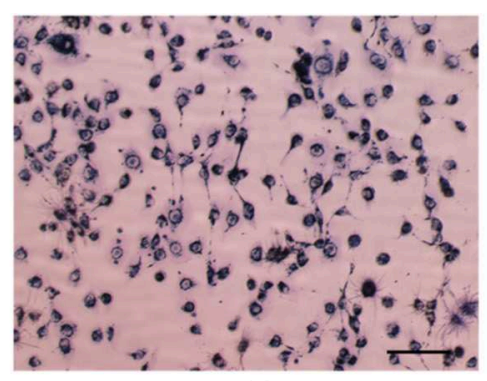

B

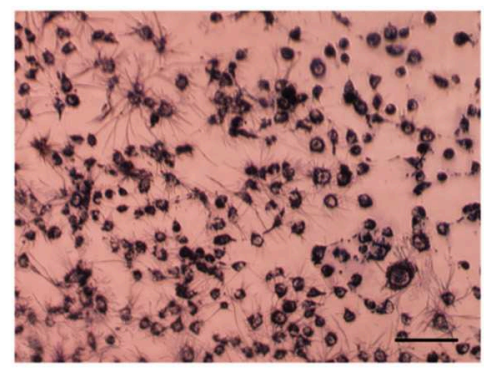

E

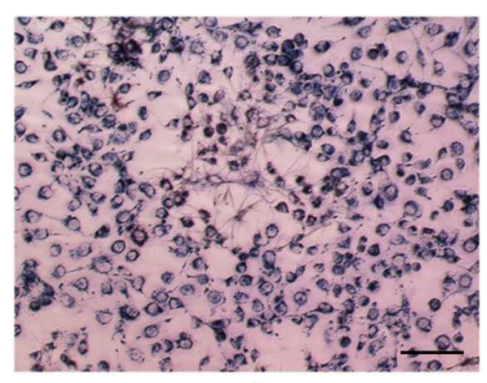

C

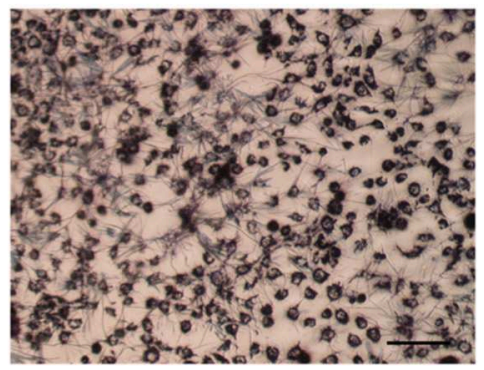

$\mathbf{F}$

FIGURE 5 | Optical images of HUVEC cells with (D-F) or without (A-C) growth factor after cultured 1 day (A,D), 2 days (B,E), and 3 days (C,F). Cell seeding density is 4,000/well. Cells were stained by MTT. The scale is $100 \mu \mathrm{m}$.
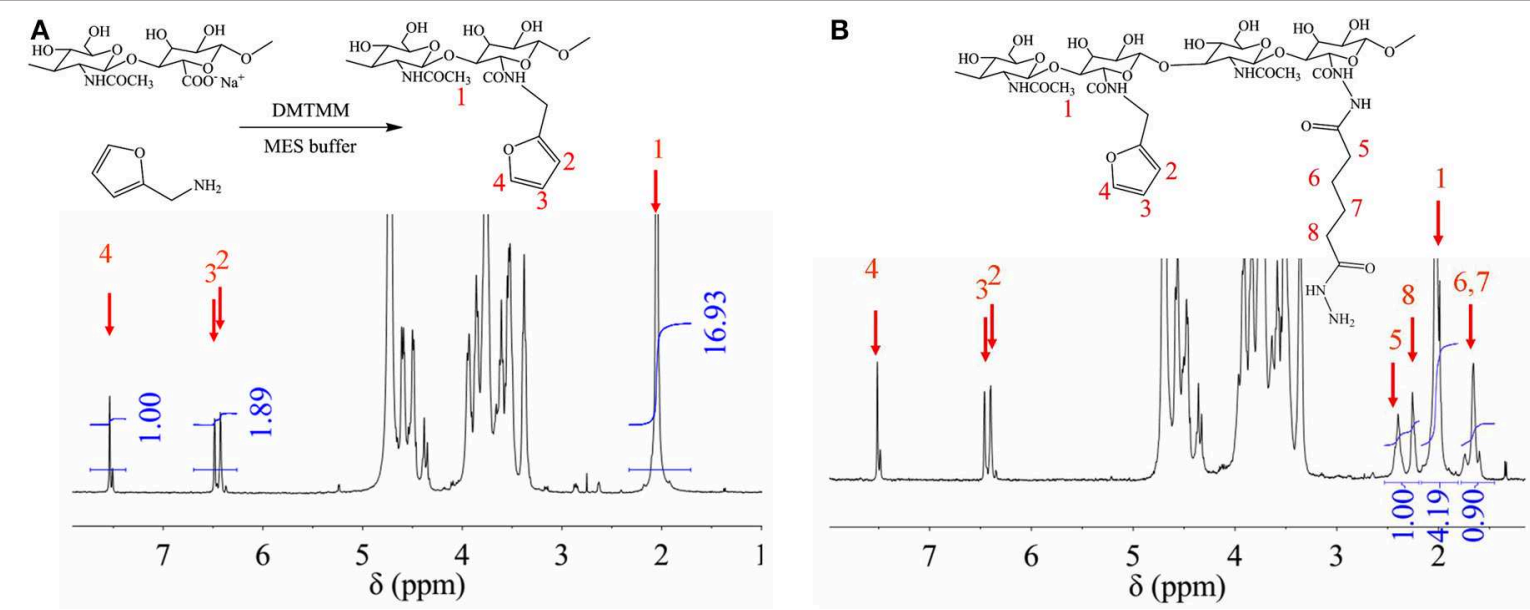

FIGURE $6 \mid{ }^{1} \mathrm{H}$ NMR of HA-furan (A), and HA-furan-ADH (B). 


\section{Fabrication and Characterization of Injectable Composite Hydrogel}

HA-furan and HA-furan-ADH were synthesized and characterized by ${ }^{1} \mathrm{H}$ NMR spectrum in Figures 6A,B. Since they are both HA derivatives, chemical shifts from 3.0 to $4.2 \mathrm{ppm}$ in both Figures 6A,B are attributed to the protons of pyranose ring. Other chemical shifts for HA-furan (Figure 6A) are listed as follows: the chemical shift at $1.9 \mathrm{ppm}$ is attributed to the protons of $\mathrm{CH}_{3}-\mathrm{O}$ at 1 position, and the chemical shifts at $6.4,6.5$, and 7.5 ppm are attributed to the protons of furan ring at 2-4 position. The chemical shift at 2-4 position confirmed successful grafting of furan onto $\mathrm{HA}$ main chain. Since the $\mathrm{H}$ number of 2-4 position in each molecule and $\mathrm{CH}_{3}-\mathrm{O}$ group every two pyranose rings are fixed, their relative area ratio could be used to calculate the substitute degree of furan group on HA, which was $17 \%$. Besides Figure 6A mentioned, chemical shifts at 1.7, 2.2, and $2.4 \mathrm{ppm}$ for HA-furan-ADH (Figure 6B) are attributed to $-\mathrm{CH}_{2}$ groups at 5-8 position, which confirmed successful grafting of
ADH onto HA-furan chain. Similarly, the substitute degree of $\mathrm{ADH}$ was calculated to be $17 \%$. In addition, HA-furan-CHO was confirmed and quantified by t-butyl carbazate assay. The substitute degree of $\mathrm{CHO}$ was calculated to be $21 \%$.

In the hydrogel system, two kinds of crosslinking points were formed to strengthen polymer network, as shown in Figure 7A. One was acyl hydrazone bond formed by $\mathrm{CHO}$ and $\mathrm{ADH}$, which was a dynamic covalent and sensitive to $\mathrm{pH}$ value. The other was formed by reversible diels-alder click chemistry between furan groups and maleimide groups. Also, properties of hydrogel were related with the double crosslinked network, which was discussed as follows. Gelation time and swelling ratio as a function of polymer concentration as well as $\mathrm{pH}$ value were investigated, which was shown in Figures 7B,C. Gelation time decreased rapidly along with polymer concentration, and swelling ratio decreased slightly with increase of polymer concentration (Figure 7B). Just as our previous research discussed, enlarged crosslinking point in definite volume increased percentage of

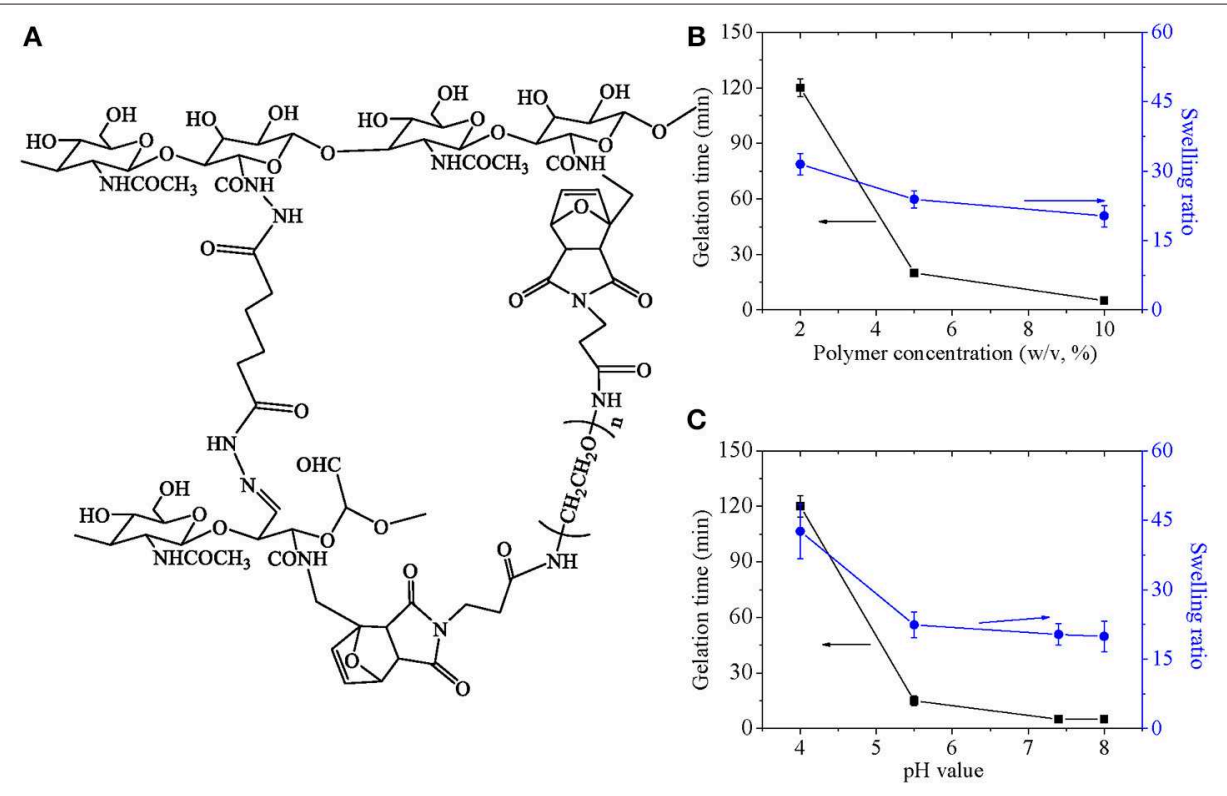

FIGURE 7 | (A) The mechanisms for the formation of the hydrazine bond and for the Diels-Adler reaction. Gelation time and swelling ratio as a function of (B) polymer concentration and $\mathbf{( C )} \mathrm{pH}$ value.
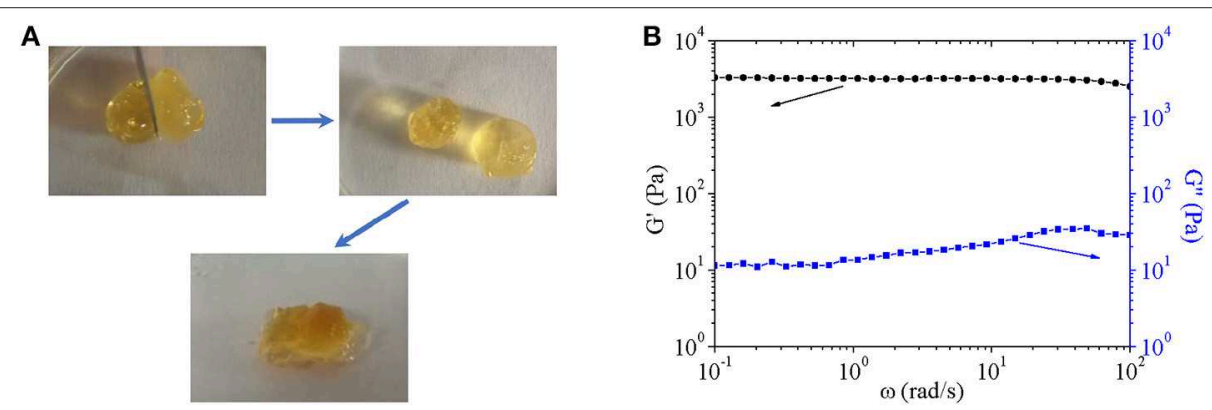

FIGURE 8 | (A) Digital images to show self-healing properties of hydrogel. The process included (1) cutting the formed hydrogel; (2) separating two part of above-mentioned hydrogel completely; (3) putting together of two separated part with complete interface touch for $24 \mathrm{~h}$. (B) Storage modulus and loss modulus of composite hydrogel. 
reaction between functional groups and accelerate reaction speed, which influenced gelation time and swelling ratio. Gelation time and swelling ratio decreased significantly with decrease of $\mathrm{pH}$ value until $\mathrm{pH} 5.5$ (Figure 7C). Since acyl hydrazone bond was formed at high $\mathrm{pH}$ value medium and broken at low $\mathrm{pH}$ value medium with critical point of $\mathrm{pH}$ 4.0 , it was easily understood that gelation time prolonged due to lack of one kind of crosslinkings in low $\mathrm{pH}$ value and swelling ratio enlarged due to less crosslink points. In summary, adjustable gelation time ensured the injectable property for composite hydrogel.

Furthermore, the self-healing property was confirmed by Figure 8A. Just as above discussed, the hydrogel was crosslinked by dynamic covalent and reversible Diels-alder click chemistry, which endowed hydrogel flexible and reversible crosslinking points. The characteristic gave self-healing property to hydrogel.

Finally, composite hydrogel was characterized by gelation time and swelling ratio, which possessed similar properties to pure hydrogel. Additionally, viscoelastic behaviors of composite hydrogels were shown in Figure 8B. Storage moduli of hydrogel was around $3 \times 10^{3} \mathrm{~Pa}$, which was 100-300 times higher than loss moduli of 100-300 $\mathrm{Pa}$ over the frequency range of $10^{-1}-10^{2}$ $\mathrm{rad} / \mathrm{s}$. The result indicated that composite hydrogels had typical characteristics of elastomers. With increasing angular frequency, storage moduli showed little decrease and loss moduli increased gently with no sign of breakage as far as the measured angular frequency range was concerned. The mechanical property ensured its potential application as a scaffold.
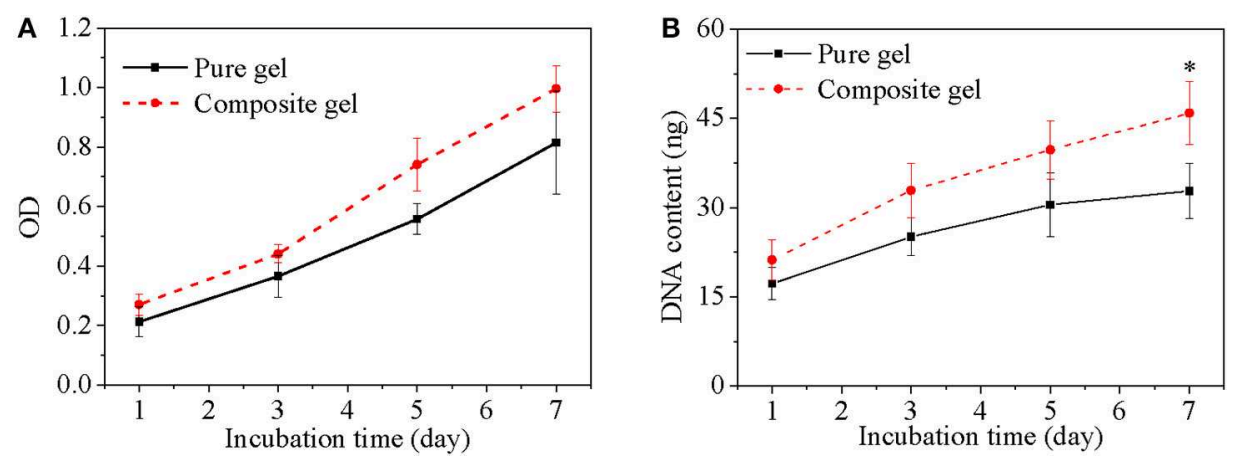

FIGURE 9 | Cell viability (A) and DNA content (B) of cells in different gels as a function of culture time. cell density is $400,000 / g e l .{ }^{*} p<0.05$.

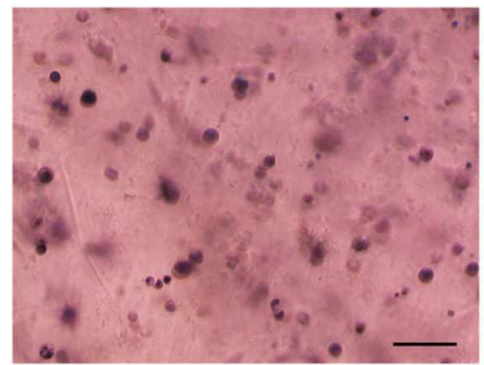

A

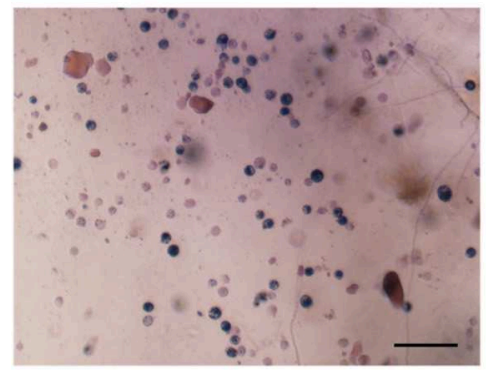

D

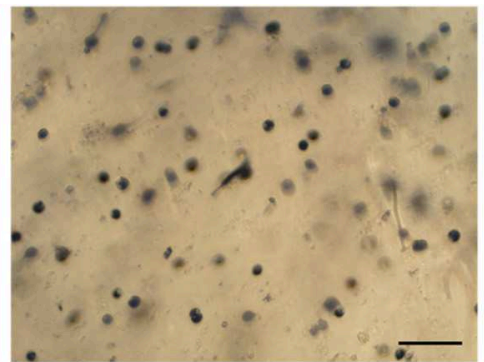

B

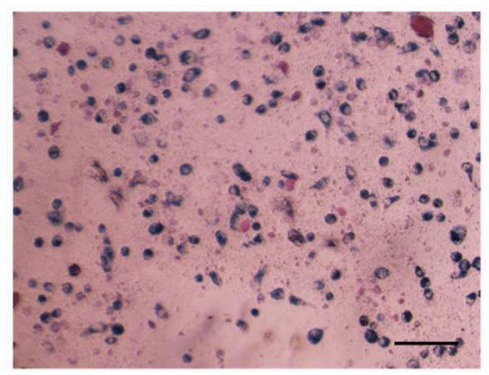

E

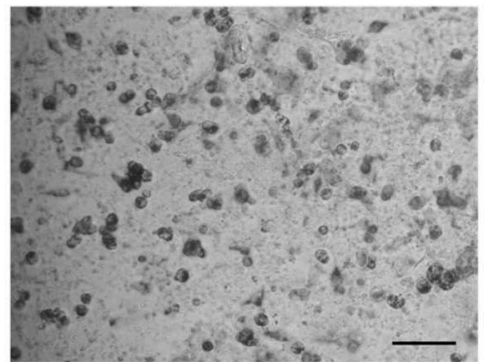

C

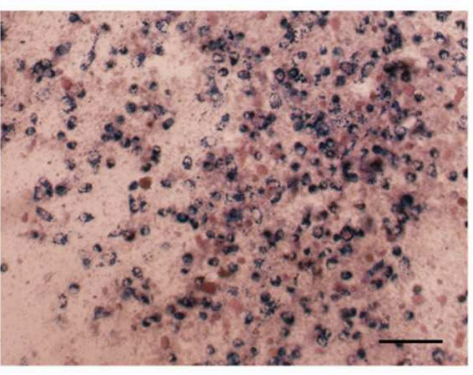

F

FIGURE 10 | Optical images of cells in gels without (A-C) or with (D-F) growth factor encapsulated nanoparticle after cultured 1 day $(\mathbf{A}, \mathbf{D}), 3$ days (B,E), and 5 days (C,F). Cell seeding density is 400,000/gel. Cells were stained by MTT. The scale is $100 \mu \mathrm{m}$. 
Moreover, the degradation of both pure hydrogel and composite hydrogel was about 3 weeks. No significant difference for degradation time was found between hydrogel and composite hydrogel.

\section{In vitro Evaluation for Composite Hydrogel}

Cell was incorporated into composite hydrogel to evaluate its biomedical application using pure hydrogel without nanoparticle as a control. Cell viability both in either pure hydrogel and in composite hydrogel increased obviously along with culture time and the increase have statistically significant difference (Figure 9A), which indicated that either pure hydrogel or composite hydrogel can support cell growth. Moreover, cell viability in composite hydrogel was higher than that in pure hydrogel especially after cells were cultured for 3 days (Figure 9A). Especially, for 5 and 7 days, the difference between composite hydrogel and pure hydrogel has obvious statistical significance. Higher cell viability in composite hydrogel was ascribed to encapsulated growth factor. Similarly, DNA content of either pure hydrogel or composite hydrogel increased significantly along with culture time. While DNA content of composite hydrogel was higher than that of pure hydrogel especially after cells were cultured for 3 days (Figure 9B). Just as above discussed, DNA content reflects cell number. Hence hydrogels could support cell proliferation and composite hydrogel could accelerate cell proliferation more. Furthermore, cells in hydrogels exhibited round morphology, which was recorded by microscope in Figure 10. At day 1, some round cells homogenous dispersed in hydrogels (Figures 10A,D); at day 3, homogenous dispersed cells increased (Figures 10B,E); at day 5 , cells increased further (Figures 10C,F). Overally, cell number in composite hydrogel (Figures 10D-F) was obvious larger than that in pure hydrogel (Figures 10A-C). Therefore, these results were consistent and confirmed that hydrogels could maintain cell activity and support cell growth, and composite hydrogel possessed better properties.

\section{CONCLUSION}

$\mathrm{pH}$-sensitive bifunctional nanoparticle was successfully prepared by combined $\mathrm{W} / \mathrm{O} / \mathrm{W}$ technique and in situ polymerization. Final nanoparticle exhibited homogeneous sphere morphology and biphase structure. $\mathrm{pH}$ sensitive property of the nanoparticle was confirmed by effective diameter change from $314 \mathrm{~nm}$ in PBS to $299 \mathrm{~nm}$ in acid solution as well as zeta potential change. The growth factor encapsulated capacity in the nanoparticle was influenced by initial growth factor concentration with maximum

\section{REFERENCES}

Akuta, T., Kikuchi-Ueda, T., Imaizumi, K., Oshikane, H., Nakaki, T., Okada, Y., et al. (2015). Expression of bioactive soluble human stem cell factor (SCF) from recombinant Escherichia coli by coproduction of thioredoxin and efficient purification using arginine in affinity chromatography. Protein Expr. Purif. 105, 1-7. doi: 10.1016/j.pep.2014. 09.015 encapsulated amount of $1.9 \mathrm{ng} / \mathrm{mg}$ nanoparticle. Their release behaviors were dependent on $\mathrm{pH}$ value of released medium. Detailedly, about $60 \%$ could be released in $24 \mathrm{~h}$ in PBS; but nearly all the growth factor dispersed homogeneously in $\mathrm{pH} 5.5$ medium after $1 \mathrm{~h}$. In vitro investigation including cell viability, DNA content and cell morphology revealed that the released growth factor could increase cell viability and promote cell growth. In further step, HA-furan, HA-furan-ADH, and HA-furan-CHO were successfully synthesized with furan substitute degree of $17 \%$, $\mathrm{ADH}$ substitute degree of $17 \%$, $\mathrm{CHO}$ substitute degree of $21 \%$. Hydrogel was crosslinked by dynamic covalent and reversible diels-alder click chemistry, which endowed hydrogel flexible and adjustable properties including self-healing property. Gelation time and swelling ratio were influenced by $\mathrm{pH}$ value and polymer concentration. Higher polymer concentration or higher $\mathrm{pH}$ value resulted in shorter gelation time and smaller swelling ratio. After nanoparticle was incorporated into hydrogel, composite hydrogel exhibited acceptable mechanical property as a scaffold for biomedical field with storage moduli of $3 \times 10^{3} \mathrm{~Pa}$ and loss moduli of 100-300 $\mathrm{Pa}$. In vitro evaluation from viability, DNA content and cell morphology results confirmed that hydrogels could maintain cell activity and support cell growth, and further composite hydrogel possessed better properties.

\section{DATA AVAILABILITY}

The raw data supporting the conclusions of this manuscript will be made available by the authors, without undue reservation, to any qualified researcher.

\section{AUTHOR CONTRIBUTIONS}

$\mathrm{XH}$ provided an idea, designed the whole research, and write the manuscript. ZG synthesized and characterized materials, give evaluations for the injectable composite hydrogel. HT helped to perform in vitro evaluation. HW prepared nanoparticle and helped to culture cells. XM helped to synthesize and characterize materials. JP helped to characterize materials.

\section{FUNDING}

This study is financially supported by Natural Science Foundation of Jiangsu Province (BK20171113), Natural Science Foundation of China (21702082), Qing Lan Project, Six talent peaks project in Jiangsu Province (JY-071), Excellent scientific and technological innovation team of Jinling institute of Technology. 
Banerjee, S. L., and Singha, N., K. (2017). A new class of dual responsive selfhealable hydrogels based on a core crosslinked ionic block copolymer micelle prepared via RAFT polymerization and Diels-Alder "click" chemistry. Soft Matter 13, 9024-9035. doi: 10.1039/C7SM01906H

Celie, K. B., Toyoda, Y., Dong, X., Morrison, K. A., Zhang, P., Asanbe, O., et al. (2019). Microstructured hydrogel scaffolds containing differential density interfaces promote rapid cellular invasion and vascularization. Acta Biomater. 91, 144-158. doi: 10.1016/j.actbio.2019.04.027

Chen, P., Wang, X., and Hu, X., H. (2018). A new route to fabricate multifunctional and multistage composite nanoparticle. Int. J. Polym. Sci. 2018:3035629. doi: $10.1155 / 2018 / 3035629$

Chen, S. N., Hu, X. H., Gong, X., Gao, Z. G., Wang, X., and Chen, P. (2017). Synthesis and preparation of biocompatible and $\mathrm{pH}$ responsive cyclodextrin-based nanoparticle. J. Nanoparticle Res. 19:109. doi: 10.1007/s11051-017-3819-5

Fan, M., Ma, Y., Mao, J., Zhang, Z., and Tan, H. (2015). Cytocompatible in situ forming chitosan/hyaluronan hydrogels via a metal-free click chemistry for soft tissue engineering. Acta Biomater. 20, 60-68. doi: 10.1016/j.actbio.2015. 03.033

Franc, G., and Kakkar, A., K. (2009). Diels-Alder "click" chemistry in designing dendritic macromolecules. Chemistry 15, 5630-5639. doi: 10.1002/chem.200900252

Fu, S., Ni, P., Wang, B., Chu, B., Zheng, L., Luo, F., et al. (2012). Injectable and thermo-sensitive PEG-PCL-PEG copolymer/collagen/n-HA hydrogel composite for guided bone regeneration. Biomaterials 33, 4801-4809. doi: 10.1016/j.biomaterials.2012.03.040

Massaro, M., Buscemi, G., Arista, L., Biddeci, G., Cavallaro, G., D’Anna, F., et al. (2019). Multifunctional carrier based on halloysite/laponite hybrid hydrogel for kartogenin delivery. ACS Med. Chem. Lett. 10, 419-424. doi: 10.1021/acsmedchemlett.8b00465

Muraoka, K., Le, W., Behn, A. W., and Yao, J. (2018). The effect of growth differentiation factor 8 (Myostatin) on bone marrow-derived stem cell-coated bioactive sutures in a rabbit tendon repair model. Hand. doi: 10.1177/1558944718792708. [Epub ahead of print].

Oh, S. H., An, D. B., Kim, T. H., and Lee, J., H. (2016). Wide-range stiffness gradient PVA/HA hydrogel to investigate stem cell differentiation behavior. Acta Biomater. 35, 23-31. doi: 10.1016/j.actbio.2016.02.016

Psarra, E., Foster, E., Konig, U., You, J., Ueda, Y., Eichhorn, K. J., et al. (2015). Growth factor-bearing polymer brushes-versatile bioactive substrates influencing cell response. Biomacromolecules 16, 3530-3542. doi: 10.1021/acs.biomac.5b00967

Song, H., Zhang, Y., Cheng, P., Chen, X., Luo, Y., and Xu, W. (2019). A rapidly selfassembling soft-brush DNA hydrogel based on RCA products. Chem. Commun. 55, 5375-5378. doi: 10.1039/C9CC01022J
Song, L., Liang, X., Yang, S., Wang, N., He, T., Wang, Y., et al. (2018). Novel polyethyleneimine-R8-heparin nanogel for high-efficiency gene delivery in vitro and in vivo. Drug Deliv. 25, 122-131. doi: 10.1080/10717544.2017.1417512

Thanusha, A. V., Dinda, A. K., and Koul, V. (2018). Evaluation of nano hydrogel composite based on gelatin/HA/CS suffused with Asiatic acid/ZnO and $\mathrm{CuO}$ nanoparticles for second degree burns. Mater. Sci. Eng. C Mater. Biol. Appl. 89, 378-386. doi: 10.1016/j.msec.2018.03.034

Wang, C. Z., Eswaramoorthy, R., Lin, T. H., Chen, C. H., Fu, Y. C., Wang, C. K., et al. (2018). Enhancement of chondrogenesis of adipose-derived stem cells in HA-PNIPAAm-CL hydrogel for cartilage regeneration in rabbits. Sci. Rep. 8:10526. doi: 10.1038/s41598-018-28893-x

Wang, X., Zhang, L., Wang, H. M., and Hu, X., H. (2018). A magnetic and $\mathrm{pH}$-sensitive composite nanoparticle for drug delivery. J. Nanomater. 2018:1506342. doi: 10.1155/2018/1506342

Williams, D. L., Wirostko, B. M., Gum, G., and Mann, B., K. (2017). Topical crosslinked HA-based hydrogel accelerates closure of corneal epithelial defects and repair of stromal ulceration in companion animals. Invest. Ophthalmol. Vis. Sci. 58, 4616-4622. doi: 10.1167/iovs,.16-20848

Wu, W., Yao, W., Wang, X., Xie, C., Zhang, J., and Jiang, X. (2015). Bioreducible heparin-based nanogel drug delivery system. Biomaterials 39, 260-268. doi: 10.1016/j.biomaterials.2014.11.005

Yu, F., Cao, X., Zeng, L., Zhang, Q., and Chen, X. (2013). An interpenetrating $\mathrm{HA} / \mathrm{G} / \mathrm{CS}$ biomimic hydrogel via Diels-Alder click chemistry for cartilage tissue engineering. Carbohydr. Polym. 97, 188-195. doi: 10.1016/j.carbpol.2013.04.046

Zhao, Q., Zhao, Y., Lu, Z., and Tang, Y. (2019). Amino acid-modified conjugated oligomer self-assembly hydrogel for efficient capture and specific killing of antibiotic-resistant bacteria. ACS Appl. Mater. Interfaces. 11, 16320-16327. doi: 10.1021/acsami.9b02643

Zhu, Q., Jiang, M., Liu, Q., Yan, S., Feng, L., Lan, Y., et al. (2018). Enhanced healing activity of burn wound infection by a dextran-HA hydrogel enriched with sanguinarine. Biomater. Sci. 6, 2472-2486. doi: 10.1039/C8BM00478A

Conflict of Interest Statement: The authors declare that the research was conducted in the absence of any commercial or financial relationships that could be construed as a potential conflict of interest.

Copyright (C) $2019 \mathrm{Hu}$, Gao, Tan, Wang, Mao and Pang. This is an open-access article distributed under the terms of the Creative Commons Attribution License (CC $B Y)$. The use, distribution or reproduction in other forums is permitted, provided the original author(s) and the copyright owner(s) are credited and that the original publication in this journal is cited, in accordance with accepted academic practice. No use, distribution or reproduction is permitted which does not comply with these terms. 